\title{
Latin America and the Dracula problem
}

Sir - In your supplement on Science in Latin America, you discuss the relationship between scientists and Mexican industry, but fail to address the question of the development of a scientific culture among the population at large (Nature 398 Suppl. 1 April, A7-A9; 1999). This is an important issue, especially as in Latin American countries the health of the research enterprise may depend strongly on its coupling to both education and science popularization among the wider public.

Our societies are rapidly moving in many different cultural directions, but so far science has been largely absent or has played a token role. Science popularization in Mexico is hardly facilitated by the academic establishment. We have excellent science museums, but many institutions and researchers are contemptuous of efforts to promote public understanding of science, an activity which is unfairly considered a flamboyant, second-rate endeavour. In Mexico a significant portion of a researcher's salary comes from supplements that reflect the number of articles published in refereed journals. Such a policy discourages creative involvement in promoting public understanding of science.

This is a mistake. Like Count Dracula, science should always be on the lookout for fresh blood. Half of our population is aged 15 years or less. To expose young people to an environment in which science is recognized as an essential component of modern culture should be seen as an international responsibility. The intellectual potential destroyed by discouraging a student in a developing country from pursuing a career in science is a loss not only for their country, but for the global scientific community. Such losses could be mitigated by developing multinational efforts to promote science, eagerly but without paternalistic attitudes, with the assistance of international scientific societies and organizations [see Commentary in this issue, page 633].

This task cannot be merely pedagogical, nor restricted to the utilitarian aspects of scientific research. It is not an easy endeavour, yet we have extraordinary precedents. In colonial Mexico in the late eighteenth century, Jos Ignacio Bartolache, a physician, founded El Mercurio Volante, a small newspaper that published advances in medicine, chemistry, physics and astronomy. Bartolache sometimes wrote not only in Spanish, but also in Nahuatl, one of our main Indian languages, so that the benefits of knowledge would be available to a wider segment of the population. A mad, heroic effort. But shouldn't every pioneer have a dose of quixotic blood running in their veins? Antonio Lazcano

Facultad de Ciencias, Universidad Nacional Autonoma de Mexico, Apdo Postal 70-407, Cd Universitaria, 04510 Mexico D.F., Mexico

\section{Speaking up for our}

\section{Japanese colleagues}

Sir - I have just returned from yet another seminar where the speaker scrupulously named all his colleagues and competitors when referring to their work, except for those from Japan, who were lumped together as "a Japanese group".

As I assume that most of my fellow scientists are not racists, I can only infer that they are too lazy and/or discourteous to bother to remember unfamiliar Japanese names.

If Japanese scientists can learn Western names, why can't we learn theirs?

Kathy Weston

CRC Centre for Cell and Molecular Biology,

237 Fulham Road, London SW3 6JB, UK

\section{Extinction needn't}

\section{be for ever}

Sir - The questions raised by Peter D. Moore $^{1}$ in connection with the discovery ${ }^{2}$ of the wild gametophytes of the celebrated British rarity, Killarney fern (Trichomanes speciosum) are of great significance. Moore questions the appropriateness of declaring a plant species extinct without being sure that the last individual has been wiped out. We would like to examine these issues in the Indian context, where the appearance of new taxa, extinction and rediscoveries go hand in hand.

It has been predicted that, in the next few decades, one-third of Indian biodiversity may become extinct or nearly extinct ${ }^{3}$. At present, the rarity of Indian plants is commonly inferred from herbarium data. If a species has not been collected within the past 50 years, it is considered 'possibly extinct' . This highly biased concept has led to the rediscovery of many 'extinct' plants when they were searched for thoroughly. Nearly 60 Indian endemic species have been rediscovered in this way during 1990-98, for example Cynometra bourdillonii, Dialium travancoricum, Humboldtia bourdillonii, Inga cynametroides, Taeniophyllum scaberulum and Aenhenrya rotundifolia. Some papers report the rediscovery of more than a dozen 'extinct' species.

These rediscoveries are directly related to the amount of collecting effort invested, and we believe that most tropical (rather than temperate) 'extinction' is actually nonavailability of data rather than genuine extinction. No Indian biologist has yet questioned the credibility of these reports. We suggest that the Indian plants classified as extinct because they have not being collected recently should instead be termed 'plants to be rediscovered'. This may save the word 'extinction' from constant misuse.

Pointing out examples of plants that have been considered extinct but then reestablished from seed banks, Moore suggested ${ }^{5}$ that monitoring of the soil seed or spore bank should be mandatory before designating a plant as extinct. But is this possible in a country such as India, where the search for the mature plant itself is a difficult task; where biodiversity documentation is incomplete; and where taxonomists themselves are 'critically endangered' owing to lack of funding ${ }^{6}$ ? K. P. Rajesh, P. V. Madhusoodanan Department of Botany, Calicut University, Kerala 673 635, India

1. Moore, P. D. Nature 392, 661-662 (1998).

2. Rumsey, F. J., Jermy, A. C. \& Sheffield, E. Watsonia 22, 1-19 (1998).

3. Gadgil, M. \& Meher-Homji, V. M. in Conservation in Developing Countries: Problems and Prospects (eds Danniel, J. C. \& Serrao, J. S.) 175-197 (Bombay Natural History Society, 1990).

4. Jain, S. K. \& Sastry, A. R. K. in Biological Aspects of Rare Plant Conservation (ed. Synge, H.) 59-66 (Wiley, New York, 1981).

5. Moore, P. D. Nature 303, 572 (1983).

6. Khoshoo, T. N. Curr. Sci. 69, 14-17 (1995).

Proposed GMO rules lack scientific sense

Sir-Your article about negotiations on the global regulation of genetically modified organisms (GMOs) omitted much of the essential context of this ill-conceived undertaking (Nature 398, 6; 1999).

It is misleading to represent the lack of agreement at the talks as a "conflict between trade and environmental concerns".

'Pseudo-environmental concerns' would be more apt. The scientifically insupportable scope of the proposed biosafety protocol focuses regulatory attention on experiments of largely negligible risk. It 
covers GMOs, but no other organisms, no matter how pathogenic or otherwise dangerous to the environment.

Ironically, the protocol would burden with unscientific, expensive and unnecessary regulation environmentfriendly products that can be produced by recombinant DNA technology, and which are needed by developing countries.

US negotiators at the talks in Cartagena could have argued persuasively that the proposed regulations lack scientific and common sense, but their position instead focused exclusively on trade considerations, aiming to protect agribusiness interests.

The United Nations' proposed protocol would make GMOs artificially expensive to test, produce and use. According to a US Department of Agriculture study, the prices of wheat and coarse grains (corn, barley and sorghum) could increase worldwide by an average of 2 per cent and 5.6 per cent, respectively. Developing countries would spend more on food and be prevented from participating in technological trends.

Future talks should be based on scientific principles, actual product risk and the public interest, rather than politics, expediency and narrow self-interest. Henry I. Miller

Hoover Institution,

Stanford, California 94305-6010, USA

\section{Others should follow the} US line on bioweapons

Sir-Your article on the controversy surrounding destruction of the smallpox virus presented well the difficult and complicated issues facing international policy-makers (Nature 398, 741; 1999). But one statement attributed to me was seriously in error. It is alleged that I said that the US Department of Defense wished to see stocks of variola virus retained in order to retaliate in kind should the United States be subjected to a bioweapons attack. From this, it might be implied that the United States was not intent on meeting the obligations of the Biological Weapons Convention that ban offensive weapons. That would be a serious matter indeed.

The US stock of offensive weapons was destroyed more than 20 years ago. During my years of government service, I know of no one who ever suggested using biological weapons in retaliation or in any other manner. One would hope that this might one day be the accepted norm for all countries.

\section{A. Henderson}

Center for Civilian Biodefense Studies, Johns Hopkins University, Candler Building, Suite 850, 111 Market Place, Baltimore, Maryland 21202-6907, USA

\section{There's still a place for physics out west}

Sir — Tony Reichhardt's article, "Wyoming physics faculty faces closure", grossly overstates our recommendations on the future of the Department of Physics and Astronomy at the University of Wyoming (Nature 398, 357; 1999). Since the article appeared, we have further refined our recommendations, which will clarify the future of physics instruction.

It was never suggested that the university should not teach physics. The academic plan did, however, raise serious questions about the health of the Department of Physics and Astronomy. These in turn raise questions about the number of degree programmes we will try to support. Currently, we offer bachelors, masters and doctoral degrees in physics, and a bachelors degree in astronomy/astrophysics.

Physics and astronomy is a troubled department. Last year, with a budget of more than \$1 million, it produced only one graduate with a baccalaureate degree. We have an obligation to ask whether a budget of this magnitude is justified.

There are additional problems. Our recommendation to eliminate the department's graduate programmes and to question the future of the baccalaureate degree was based largely on a 1998 peer review of the mathematics and physical sciences divisions within the university's College of Arts \& Sciences.

The reviewers, representatives from other University of Wyoming colleges as well as from other regional universities, examined six departments. Five were rated 'very good' or 'acceptable'; only physics and astronomy was rated 'unacceptable'.

The review found that, between 1992 and 1996, undergraduate enrolment fell by 44 per cent, graduate enrolment by 29 per cent, and degrees granted by 53 per cent. Enrolment in many undergraduate courses was lower than the university's standard minimum. About half the faculty members were inactive in research. Collegiality among at least some faculty members was low, and communication was a major problem. The Wyoming Infrared Observatory (WIRO) appeared to be underused and underequipped, owing in part to the staff's inability to communicate and work together.

Both this review and an evaluation of WIRO by leading astronomers also indicated that changes must be made in the administration of the observatory, to improve its cost-effectiveness, and in the quality of its instruments to improve the science. Given the many calls on this institution's limited funds, it was imperative that the academic plan should question whether this is a sensible continuing investment. To treat any discipline as a sacred cow would make a mockery of any planning process.

Since the article in Nature, we have completed our second draft of the plan. We received thousands of comments on the draft. Many comments dealt with the Department of Physics and Astronomy.

The comments did not change our view that the department is troubled. However, we were convinced that we could not have a credible department without offering at least a bachelors degree in the subject.

The new draft plan says the university's intention is to maintain a baccalaureate programme in physics, but it also places the responsibility where it belongs - on the faculty members - to rebuild the programme, beginning with the undergraduate programme. Graduate students will be able to complete their studies, but the plan suggests a moratorium on accepting new graduate students. Whether the masters or doctoral programmes are restored in the future will depend upon the progress made at undergraduate level. We will continue to look at new creative ways to manage the underused infrared telescope.

We believe that the people of Wyoming want a stronger, more focused university. We asked tough questions about every programme, including physics. The article raised the spectre of whether Wyoming would be shamed by being the only staterun university without a physics degree programme. In fact, we will maintain our baccalaureate programme and will rebuild the department, but only progressively and in response to specific benchmarks of performance. We know of no other way to preserve the quality educational experience we offer our students.

Philip L. Dubois

(President)

Tom Buchanan

(Vice-President for Academic Affairs)

University of Wyoming,

Laramie, Wyoming 82071, USA

Reichhardt replies - My News report said, in fact, that the university would still teach physics, and that not offering the bachelor's degree was only an option. I wrote: "The plan recommends that consideration be given to scrapping the bachelors degree programme and offering physics courses only as a 'service function'..." The university later chose to keep the bachelor's degree, but it was still a possibility that it would be killed off when the article was written.

Tony Reichhardt

104 Cleremont Drive, Fredericksburg,

Virginia 22405, USA 